\title{
A GEOGRAPHICAL METHODOLOGY FOR ASSESSING NODALITY OF A ROAD NETWORK. CASE STUDY ON THE WESTERN MOLDAVIA
}

Daniel Tudora, Mihail Eva

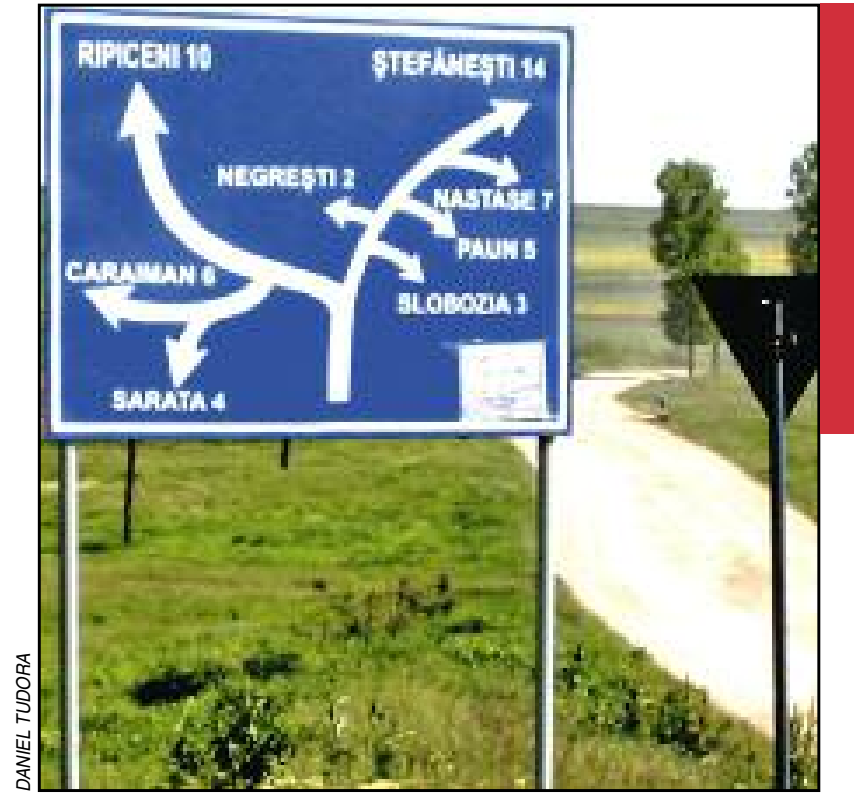

Road network is an important landscape element. 


\title{
A geographical methodology for assessing nodality of a road network. Case study on the western Moldavia
}

DOI: http://dx.doi.org/10.3986/AGS54107

UDC: 911.3:656(478)

COBISS: 1.01

\begin{abstract}
The study tests the concept of nodality in a three-dimensional space, both as a projection of the physical-geographical support and an expression of topological centrality, which is insufficiently employed in papers attempting to evaluate the geographical or potential accessibility. The junctions of the reticular systems will be positioned differently within the network depending on the acquired nodality values, which may influence through their importance the potential for development of the polarized territory. By focusing on a methodology specific to nomothetic epistemology, aimed at highlighting the vulnerabilities induced by the dysfunctions within the road network and obtaining nodal hierarchies, the study allows for the extraction of legitimate relationships, which can be extrapolated beyond the particular space matrix selected for demonstration purposes only.
\end{abstract}

KEY WORDS: geography, transport geography, impeded-distance, accessibility, centrality, reticularity, roughness, Moldavia

The article was submitted for publication on November 13, 2013.

\author{
ADDRESSES: \\ Daniel Tudora, Ph. D. \\ Department of Geography, Faculty of Geography and Geology \\ University »Alexandru Ioan Cuza« of Iasi \\ Carol I Blv. 20A, 700505 Iasi, Romania \\ E-mail: tudoradaniel@yahoo.com

\section{Mihail Eva} \\ Department of Geography, Faculty of Geography and Geology \\ University »Alexandru Ioan Cuza « of Iasi \\ Carol I Blv. 20A, 700505 Iasi, Romania \\ E-mail: e_mihail@yahoo.com
}




\section{Introduction}

The concept of nodality, as it is used in the field of Transport Geography, refers to a set of properties that a place (defined geometrically as a point) fulfils a geographical network. Furthermore, from the perspective of graph theory, any point benefits from its own nodality, with the implicit condition that the graph is connected. From these perspectives, the concept was constantly approached by geographers (see for example Ducruet 2008 for the field of transportion geography; Matthiessen et al. 2006 and 2002 for urban geography), but in the case of synthetic works in the field, it is either avoided, either given a secondary importance. Thus, from six reference works in geography of transportation, published over the last two decades (Rodrigue et al. 2009; Knowles et al. 2008; Black 2003; Banister 2002; Taaffe et al. 1996; Mérenne 1995), none is explicitly presenting the importance of indicators of nodality for geographical studies. Furthermore, the term of nodality is rarely used, no more than twice per piece of work.

The study of nodalities in the field of transportation geography is even more important since in the actual context of globalisation and dilution of national borders, permanent repositioning and redefinition of nodal points occur. As Knowles simply puts it, »nodal situations change and the spatial qualities of centrality and intermediacy enhance the importance of strategically located hubs (Knowles 2006). Furthermore, the nodality is subject to trans-scalarity, its values being significantly different depending on the scale of analysis (see Debrie et al. 2005 for an example on the port nodalities).

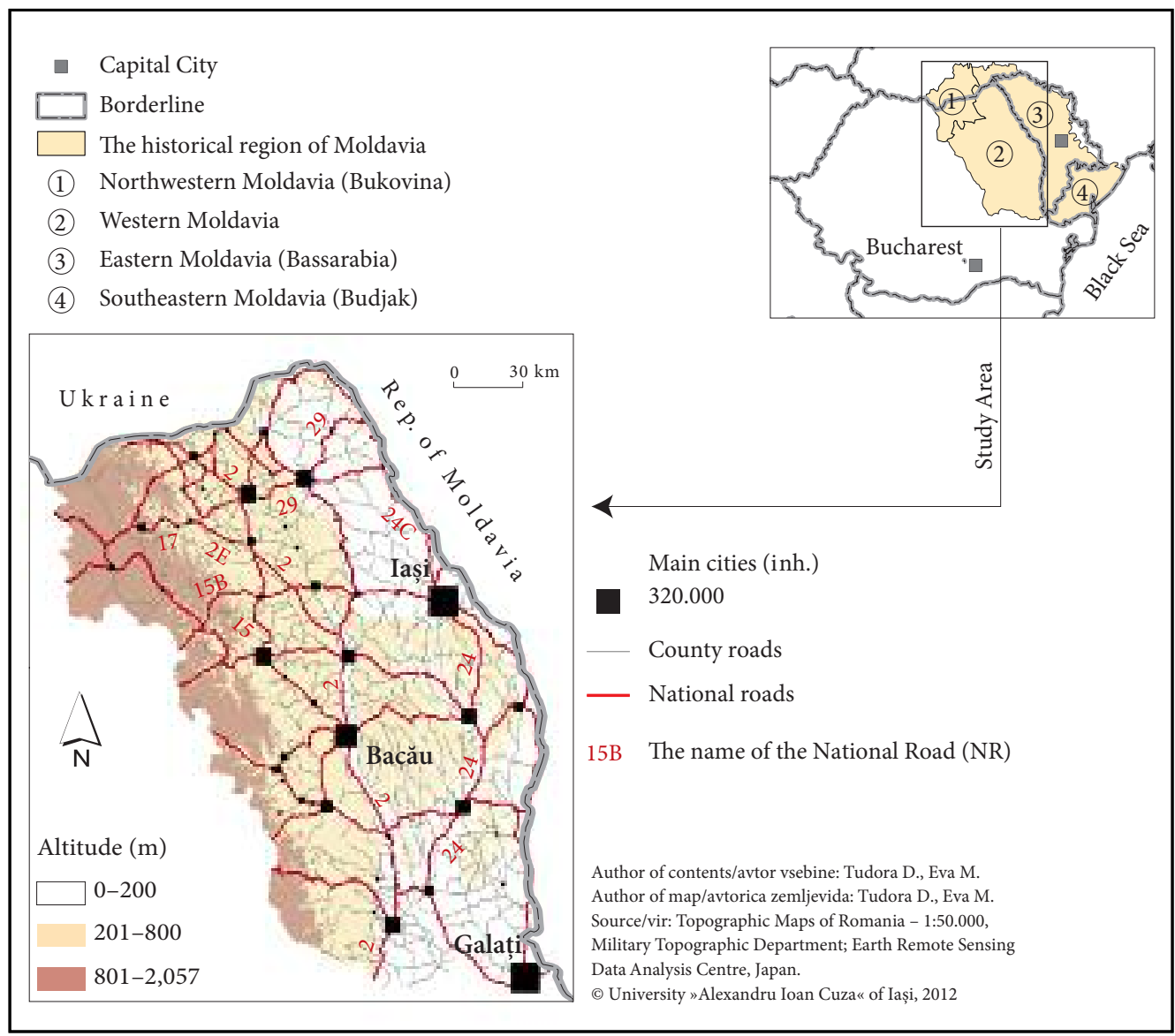

Figure 1: The study area as part of the historical region of Moldavia. 
In this regard, the present article proposes a trans-scalar methodology for assessing nodality with the purpose of determining incoherences and vulnerabilities of a given reticular space. Nodality is seen as an internal feature of the reticular system, not to be confused with centrality and intermediacy as defined by Fleming and Hayuth (1994). The present article takes nodality as a property assigned initially only to the junctions of the network, but then transfers it through proximity and spatial interaction rules to neighbouring areas, taking into consideration the morphological aspects of the network (including the influence of topography) and the demographical aspects of settlements.

In the three-dimensional reticular environments, the space allows the interpreter to identify the friction that topography imprints on the network communication paths. The new topological context has the advantage of extracting, beyond the rigidity of a flat/predictable surface, the roughness with which the physical-geographical parameters lead to the occurrence rhythm rupture inside the network. Therefore, spaces select and are differentially selected, depending on certain features of cost and efficiency, the ability to reach them and from them being disturbed by the difficulty with which they manage to put in place fast routes, regardless of topography imperfections. The intensity and the frequency through which the support-environment creates and transfers geographical determinism produce disabilities within the routes communication systems, generating vulnerability to it. A vulnerable system of communication routes always involves additional costs in terms of time, waiting, or other costs resulting from delays or deviations (see Berdica 2002 for an overview). From a geographical point of view, the evolution of the vulnerability of a network, combined with the low resilience of socio-spatial systems including them, produces various forms of risk: isolation / claustration, disconnection / decoupling, divergence / territorial fragmentation.

The support-testing region for the hypothesis was chosen for having a common evolution of the network of communication routes. The eight Romanian counties included in the study area, with a surface of $46,000 \mathrm{~km}^{2}$ and a total population of 4.7 million at the last census, represent nowadays a part of the historical region of Moldavia integrated into the Romanian territory since the formation of the modern Romanian state in the mid-nineteenth century (see Muntele et al. 2009 for an overview). The only exception is represented by the South Bukovina, a $5,000 \mathrm{~km}^{2}$ area annexed to Romania after the First World War (figure 1).

\section{Methodology}

Peculiarities of the road network in Moldavia will be highlighted through the synthesis of methods specific to the analysis of reticular, planiform, and punctiform space structures. Since the ultimate goal of the study is to obtain models of functionality in the network, final products of the research will have several utilities. They are as follows: assessing / quantifying the role of physical-geographical factor in the deterioration of connectivity indices, extraction of the points with high nodality and identifying the dysfunctional ones, and posting a graphic synopsis underpinning the optimization models of connectivity.

To obtain the final models the three steps will be followed (figure 2):

a) Road network in Moldavia will be transformed into a graph in which vertexes will be represented by the junction of county and national roads. This yields to 1,240 road segments (arcs) and 881 junctions (nodes). The length of segments will be weighted by two parameters: sinuosity and slope. In this way, the obtained graph becomes a weighted graph, measured by an impeded-distance that expands or contracts space depending on the specific roughness.

b) Network centrality to the settlement systems of the region will be evaluated based on the potential interaction between area of influence of the graph nodes and the demographic barycentres of each reference system (natural, micro-regional, and regional). Distance parameters will use the distance-impedance determined in the previous step. Through this process, three types of adjusted nodality will be obtained: at the over-local, micro-regional, and regional level.

c) Total nodality for each junction will be calculated by means of progressive/ trans-scaling aggregation between the three types of adjusted nodality, where the natural nodality has the highest share. The nodal hierarchy of road segments within the network will be calculated as the arithmetic mean between the nodal values that load each junction and the determination of vulnerabilities of the reticular space of Moldavia will be extracted through a multivariate analysis.

For the calculations and the spatial analysis we made use of ArcGIS 9.3. 


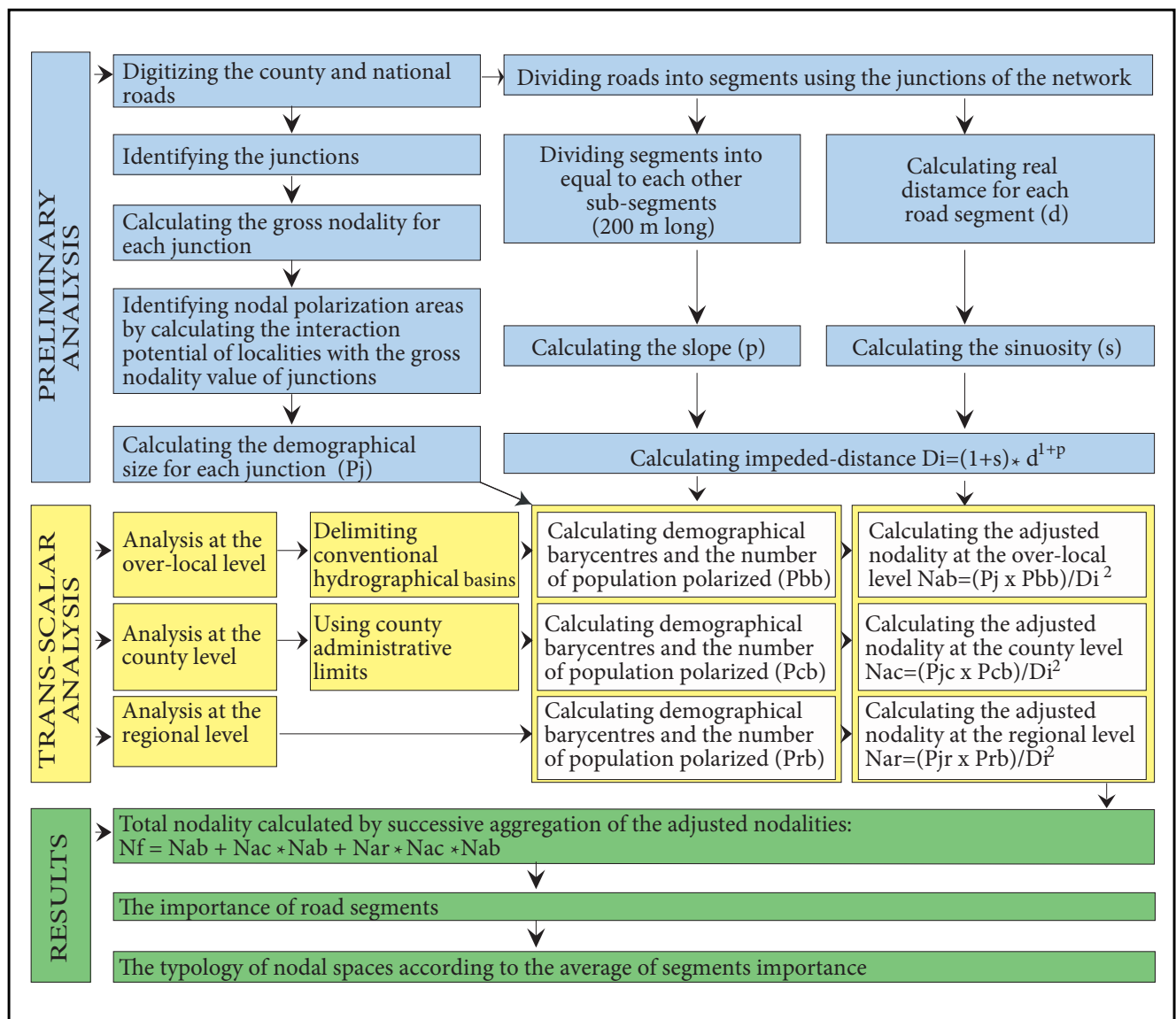

Figure 2: Guideline on the methodology for identifying the spatial structures generated by nodality.

\section{Preliminary analysis}

Connecting lines within a graph created by road network should be seen in their value dimension, actually representing distances/expressions of the spatial cost. Distances can be expressed in metric, temporal or cost dimensions, each with its own advantages and disadvantages (see Curl et. al. 2011 for an overview). Using metric distances seems obsolete since the new GIS technologies makes possible to calculate, with a relatively high precision, the temporal distances (Berke and Shi 2009; Salonen et al.; Shaw 2006) or the economic ones (cf. Combes and Lafourcade 2005). The latter are however dependent on the technological or economic conditions of the moment, reason for being susceptible to contextual changes. What appears to remain a permanent constraint for a more efficient functioning of the road network are its physical characteristics (sinuosity, slope), dependent on both the level of engineering techniques, but especially on the indirect influence of topography (especially for developing countries).

\subsection{Assessing the influence of the topographic support}

Although often positively correlated, roughness and altitude are different characteristics of land surface, the first with a spatial distribution that does not require uniformity, regularity and hard to comply with the inferential laws. 
In reality, the roughness is a problem of topography, being an indicator strongly correlated with the terrain slope and its aspect (Sappington et al. 2007). In order to evaluate this two dimensions of roughness and the influence it has on the road network, we made use of two indictors: a first one calculating the slope (altitude variation between two points in relation with the distance separating them), and a second one estimating the degree of route collinearity, i.e. the sinuosity.

Both indicators were estimated using topographic maps 1:50,000 (for digitizing the road network) and a Digital Elevation Model with a 30 meters resolution provided by Earth Remote Sensing Data Analysis Centre (for extracting the altitudinal values), which were considered satisfactory for calculating the sinuosity (using the Linear Proprieties ArcScript provided by Rathert 2003), but insufficient for the slope parameter. To correct deficiencies in the slope case (common in mountains due to the presence of numerous road segments that traverse areas with slopes with packed walls or with reinforced embankment), one should use a raster with a very fine resolution, close to the actual width of the road $(6 \mathrm{~m}$ for the carriageway and about $8 \mathrm{~m}$ for all parts of the platform).

Through the synthesis of the two variables of roughness, the space transmits to the network a certain friction, felt in each segment as a resistance force of the natural support, called impedance, and the associated distance will be named impeded-distance $\left(D_{i}\right)$ :

$$
\begin{gathered}
D_{i}=(1+s) \cdot d^{1+p} \\
p=\frac{\sum_{i=1}^{n} \Delta H}{d} \\
s=1-\frac{e}{d}
\end{gathered}
$$

where $D_{i}$ is the impeded-distance, $s$ - the sinuosity, $d$-the metric length of the road segment, $p$ - the slope, $\Delta H$ - the maximum difference in altitude of each road sub-segment $200 \mathrm{~m}$ long, and $e$ - the Euclidean distance between the ends of the road segment. From the formula (1), one can notice that each variable has a different impact factor: sinuosity is related to the distance by a multiplicative function, while the slope by an exponential one (friction imposed by a unit increase in the slope is greater than for a unit increase of sinuosity).

The roughness becomes an indicator able to quantify the heterogeneity of physical support and simultaneously to capture the impedance imposed on communication routes by altitude, landform energy, and topographic fragmentation.

Joining an impedance ratio leads to obtaining an impeded-distance always greater or equal to the distance actually measured, so it can be used later to calculate other types of geographical distance: time-distance, cost-distance, or economic-distance. Calculating the percentage ratio between impeded-distance and Euclidian distance, one can estimate the share of landform factor affecting distances between points, axes, and areas (figure 3).

The network of major roads of communication in Moldavia remains faithful to the conditions imposed by the topography roughness; thereby the network connectivity is vitiated by undue preference for S-N or NW-SE coupling direction. Deficiencies on the east-west connectivity are not mitigated by technical engineering innovations designed to reduce the roughness of the landform.

\subsection{Assessing the gross nodality}

Irrespective of the scale of analysis, the roads network creates junctions, which, depending on the proximity between them, will provide the associated spaces with the probability of interacting on various directions and configurations. As this probability is ensured easier, the administered reticular sub-systems will have a higher connectivity, will become more accessible, will stimulate emissions and attractiveness, will generate centres; hence, they will dispose of nodality. The nodality is the potential the network provides to the territory, in order to blend the real accessibility, to correct the centrality, and to generate anisotropic spaces. 


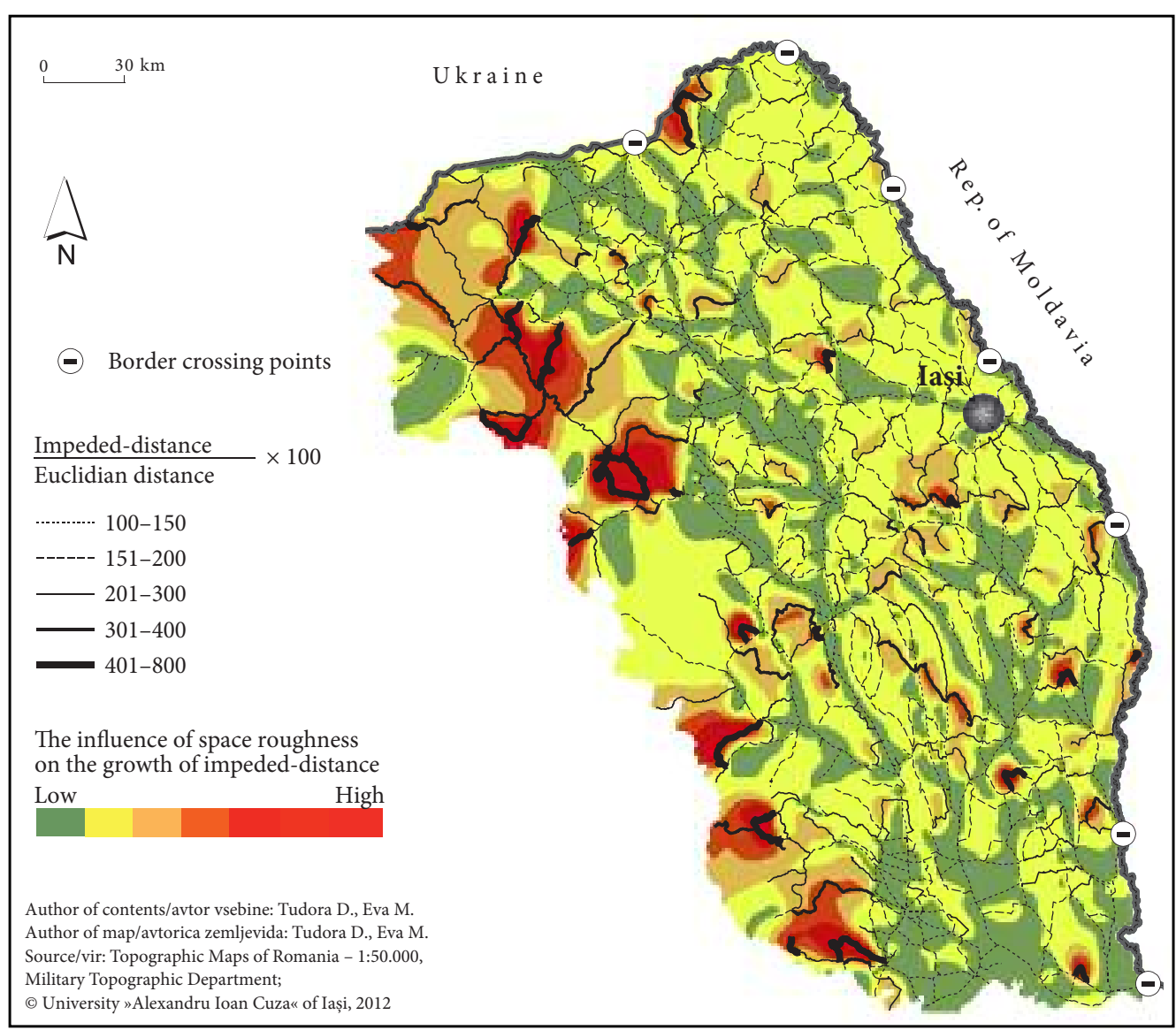

Figure 3: Space roughness influence on the growth of impeded-distance.

In the first stage of analysis, the nodality is calculated according to the concept of 'degree centrality', as an expression of local centrality (Freeman 1979). The degree of centrality involves calculating the number of edges connected to a given node. Given that the importance of road junctions within a region may depend on much more edges that are not necessarily related to the junction in question, the present article proposes calculating nodality by extracting the total number of junctions together in a buffer of $11,008 \mathrm{~km}$, i.e. the average radius of the circles circumscribing Thiessen polygons for the 881 junctions within the region. Junctions located in areas well served by the means of communication, where many intersections occur, will be loaded with a high value of nodality, unlike peripheral junctions. Resulting values vary between 1 and 26 and will be called gross nodalities (figure 4).

\section{Transscalar analysis}

In the second stage, junctions attach a nodal space, defined by the potential of interaction between them and the population points within the region. Nodal gravity increases directly proportional to the value of gross nodality and inversely proportional to the square of the distance separating the junctions from the population points.

The area of nodal influence and the potential of interaction attached to it will be used in the formula for calculating the adjusted nodality. This will be estimated depending on the demographic mass attracted 


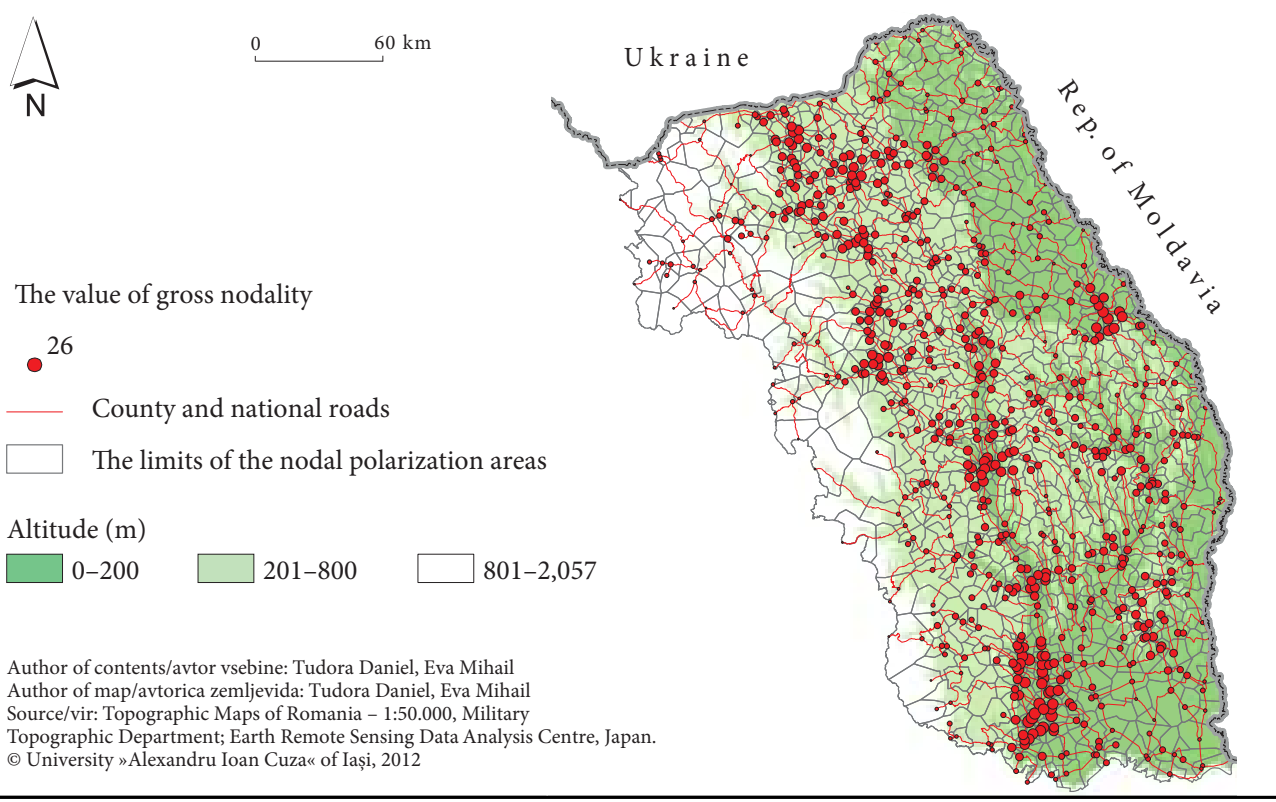

Figure 4: The gross nodality and the nodal polarisation areas.

by each nodal influence area and inversely proportional to the impeded-distance from the junction to the closest barycentre.

Because there are three categories of barycentres, each junction disposes of three types of adjusted nodality: the natural adjusted nodality, the county adjusted nodality, and the regional adjusted nodality.

\subsection{The natural adjusted nodality}

The natural adjusted nodality identifies the rapport the network maintains with the over-local spatial systems, focusing on the ability of graph nodes and segments to generate infra-territorial centrality. In addition, it notices the manner in which the ideological/driven projection of the communication routes systems neglected or overlooked the importance of discrete relations, eliminating inter-nodal competition.

In the condition of an ad litteram adaptation of social structures to the natural ones, artificial networks choose the easiest routes, dictated by the particularities of substrate: roads follow river configurations, intersections overlap with natural convergence areas, such as confluences, depressions, gathering water markets, or areas of narrowing beds.

Because modern society has persisted to ignore as far as possible the nature determinisms, but also from the necessity to produce reliable, fast, customized, and available connections, the initial network was supplemented by new segments as well as with re-accessibilizations of the pre-existing ones. The last were able to evolve to the stage in which nature had to readjust to the new nature: redrawing of river segments, including confluences, embankments, debit changes, or regularizations, cutting of slopes, intakes, undergrounding the courses of rivers, etc.

Based on gravity laws and interaction scenarios, the adjusted nodality model at the level of natural reference systems intends to notice the force through which the space (as a physical environment) was able to imprint the social systems its own trajectories, defining inertias, regularities with permanentization trends, hard to surmount by other logics, whether more efficient. In the same manner, it may be a sign stipulating deviations, repositioning and reconfigurations of socio-spatial structures, focusing on what is atypical, residual. 
The classification of hydrographical basins respected the classical methodology (Gravelius 1914), the identification of watersheds being realized on the cartographic support provided by the 1:50,000 topographic maps. Furthermore, second order basins according to Gravelius system and the largest of the third and fourth orders were divided into sub-basins, thereby achieving a relatively balanced 27 areas for which the ratio maximum area / minimum area does not exceed 1.86 .

Adjusted nodality was calculated for each node separately according to the following formula:

$$
N_{a}=P_{j} \cdot \frac{P_{b}}{D_{i}^{2}}
$$

where $N_{a}$ is the adjusted nodality, $P_{j}$ - the total population polarized by the respective junction, $P_{b}-$ the population of the polarizing barycentre, and $D_{i}$ - the impede-distance between junction and barycentre.

It should be noted that the calculation method allows each node to select its own barycentre, independently of the affiliation to a particular hydrographical basin, advantaging the junctions positioned on axis that transcend the hydrographical basins.

\subsection{The adjusted nodality at the county level}

The second nodality index personalizes the same processes reported in the case of reference system centred on conventional hydrographical basins, indicating that the establishment of clear landmarks, of administrative nature, requires for the reconfiguration mechanisms to become particular situations of the accretion and decoupling.

As in the previous case, the discourse focuses on the problem of nodal spaces that lose the centrality of their own administrative structures, being attracted through structural or serial fragmentation processes to higher nodality structures, created by differential accessibility and interaction.

The method of calculating the relations of interaction between the nodal spaces and the county barycentres allows junctions to select their own barycentre of attractiveness. The emissivity of nodal spaces is composed of two vectors: a demographical one directly proportional to the localities size which require a specific network node and a metric one inversely proportional to the distance that separates the respective junction from the barycentres likely to come into interaction with the concerned nodal space.

The highlighting of the nodal spaces not adapted to their own administrative structure on the one hand stresses the incomplete functionality of some infra-county interactions and, on the other hand, it indicates the underestimation of some distances to which big cities can impose themselves.

\subsection{The adjusted nodality at the regional level}

We underline the increased importance of the nodality centred on the city of Roman and the reticular drainage produced by the natural convergences from the median area of the Siret axis, identifying the subjective role induced by the potential factor of the place in the context of selecting such a level of connectivity analysis.

The demographical size acts secondarily in the final value of regional nodal index, while the imperceptibility originates from how each junction selects, depending on impedance and network complexity, certain preferential trajectories through which to access the centre.

Such contingencies explore historical deficiencies, warning on a north-south imbalance regarding the drainage efficiency. The latest population, the resizing of the settlements network and systems of communication routes depending on peripheral or extra-regional urban landmarks, betrays the reticular immaturity of the counties in southern Moldavia, compared to the north. Here, the filter of Christallerian balance achieved the transition from archipelago type of territorial structures to the ones related to rapid intermediary spaces. 


\subsection{The total nodality and the reticular importance of road segments}

In order to obtain the total nodality, we made use of cumulative integration of adjusted nodalities for the three levels of analysis, these being found successively in the terms of amount, and being the more influential as they are hierarchical closer to the over-local system of reference:

$$
N_{t}=N_{a b}+N_{a c} \cdot N_{a b}+N_{a r} \cdot N_{a c} \cdot N_{a b}
$$

where $N_{t}$ is the total nodality; $N_{a b}$-the adjusted nodality at the level of conventional hydrographical basins; $N_{a c}$ - the adjusted nodality at the county level; $N_{a r}$ - the adjusted nodality at the regional level.

The importance of road segments was calculated using the arithmetic mean of total nodalities related to the junctions that frame the respective segment, the roads linking important or very important crossroads being favoured.

$$
I_{s}=\frac{N_{j_{1}}+N_{j_{2}}}{2}
$$

where $I_{s}$ is the importance of road segments, $N_{j 1}$ - the total nodality for the starting junction, and $N_{j 2}-$ the total nodality for the ending junction (related to the opposite end of the segment).

Segment level analysis appreciates with greater accuracy the dysfunctions, convergences / divergences and reticular fragilities the road network in Moldavia hides (figure 5). Firstly, the segments cumulating continuous nodality are distinguishable, thus obtaining nodal linearity and becoming segments with a trans-regional character. It is true that such linearities are rare and incomplete, the only continuous section being created by NR2, opportunities for cross coupling on the east-westward direction being interrupted or disrupted for reasons of impedance or the appearance of a network capilarization process. The East Carpathians orographic barrier blocks the coherence of reticularity marked by the high values of nodality

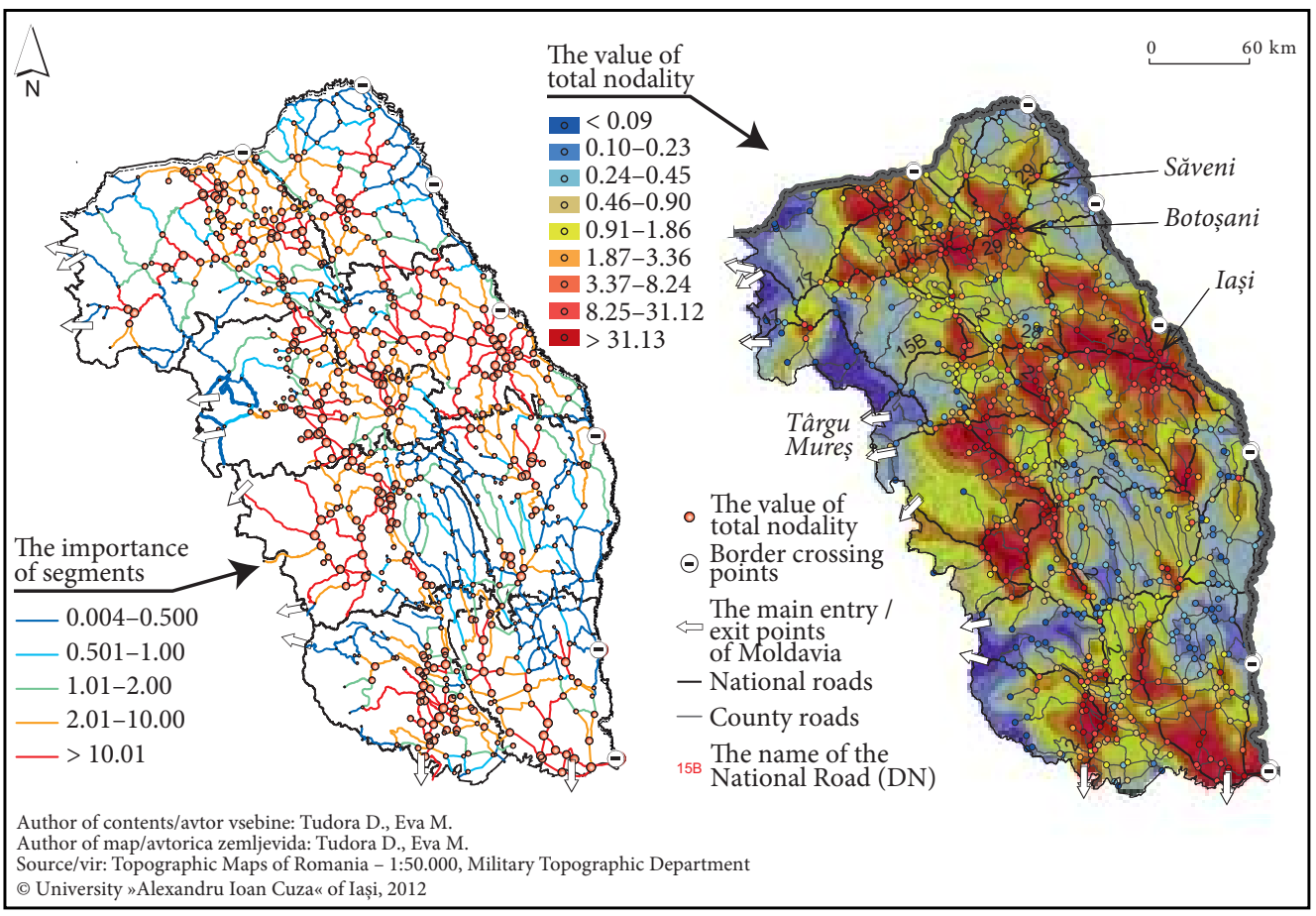

Figure 5: The importance of road segments and the total nodality. 
specific for the segments overlapping NR28 and NR15B. This barrier brings extra impedance, but further validating the choice correctness of the highway section Iaşi-Târgu-Mureş along this route. In the counties of Suceava and Botoşani, a similar case is represented by the consecutive nodalities created by NR17 and NR29, which, except for short segments nodally vitiated by impedance (due to the existence of mountain passes), maintain their reticularity up to the east of Botoşani City. Supporting a highway project along this section could solve the deficiency of regional transversality in the northern half of Moldavia.

Reticular divergences identify areas in which the segments nodality decreases from a centre with high nodal value (over-local intersections) to neighbouring areas, disadvantaged by the peripheral position within the region and by the local network inconsistency. The example given by the segments nodality centred on the Săveni town is the most convincing at the regional level. The presence of segments with such a high nodality is influenced by the ability of the intersections from Săveni town to transfer upon some short sections (10 to $20 \mathrm{~km}$ ) the nodal value made by an initial vertex. This sort of ribs with a rudimentary degree of centrality explain an inadequate maturity of the local networks and will have a negative effect on the subsequent data processing, with the capacity of corrupting the multivariate analysis at the nodal spaces level, because from the statistic point of view the convergence and the divergence will present confuse signs. The reticular hiatus are represented by spaces with very low nodality, which interfere with areas that present high nodality, having the deficiency of blocking the fluidity within the network. Their insertion within space reflects the vulnerability of reticular systems in front of the natural support roughness and compels the network to reconfiguration, which by permanentization creates inertia and behaviours specific for the anisotropic environments.

\section{Applicability and relevance of the methodology}

The analysis results can be used further to determine vulnerabilities and inconsistencies existing in a given reticular system. For this purpose, it is necessary to calculate the average importance of road segments crossing each of the 695 nodal polarisation areas. The difference between the initial number of junctions (881) and the number of polarization nodal areas (only 695 instead of 881) is due to the fact that the junctions located at distances of less than $500 \mathrm{~m}$ from each other were merged (they were considered acting as one single junction with a higher gross nodality). Furthermore, other junctions were eliminated from the analysis in the case they do not polarize any locality.

The use of the arithmetical average was preferred in the detriment of the representation of the gross values of the total nodality because of the fact that in this way one can obtain a more suggestive spatial image of the nodality at the level of polarization area by indirectly including in the formula the values of the neighbouring junctions:

$$
N_{a p}=\frac{\sum_{i=1}^{n} I_{s_{i}}}{n}
$$

where $N_{a p}$ is the average nodality at the level of the nodal polarization area, $I_{s i}-$ the importance of the road segment calculated using the formula (6), and $n$ - the number of road segments which cross the nodal polarization area. The usage of nodal polarization areas has the advantage of surprising the central spaces at regional level, dictated often by the existence of several powerful urban centres nearby, generators of convergence points between county and national roads, but it has the disadvantage of insufficient identification of the importance of lanes created by the main road communication ways.

Despite all of these deficiencies, the mapping of the nodality at the level of nodal spaces outlines several incoherencies of the reticular space of Moldavia, configured by ideological principles or by administrative attachment, being ignored the collinearities of the network at the trans-county scale or those customized within the areas of convergence generated by secondary nodalities:

- The reticular fragmentations of the sub-mountainous area situated southwest of the convergence area centred on the Onești City could be attenuated by coupling the axes situated along the rivers flowing in the area, there being many possibilities for welding some routes.

- The very low reticularity of northern part of Galați County claims a reconfiguration of the network depending on the presence of the most important road hub of the area, Bârlad City. It also depends on the border points, trans-national transfer niches of several local nodalities, significantly important for decongesting rural spaces and for stimulating commercial relations specific for areas such as dead-angle, bottom of bag, or abandoned peripheries. 


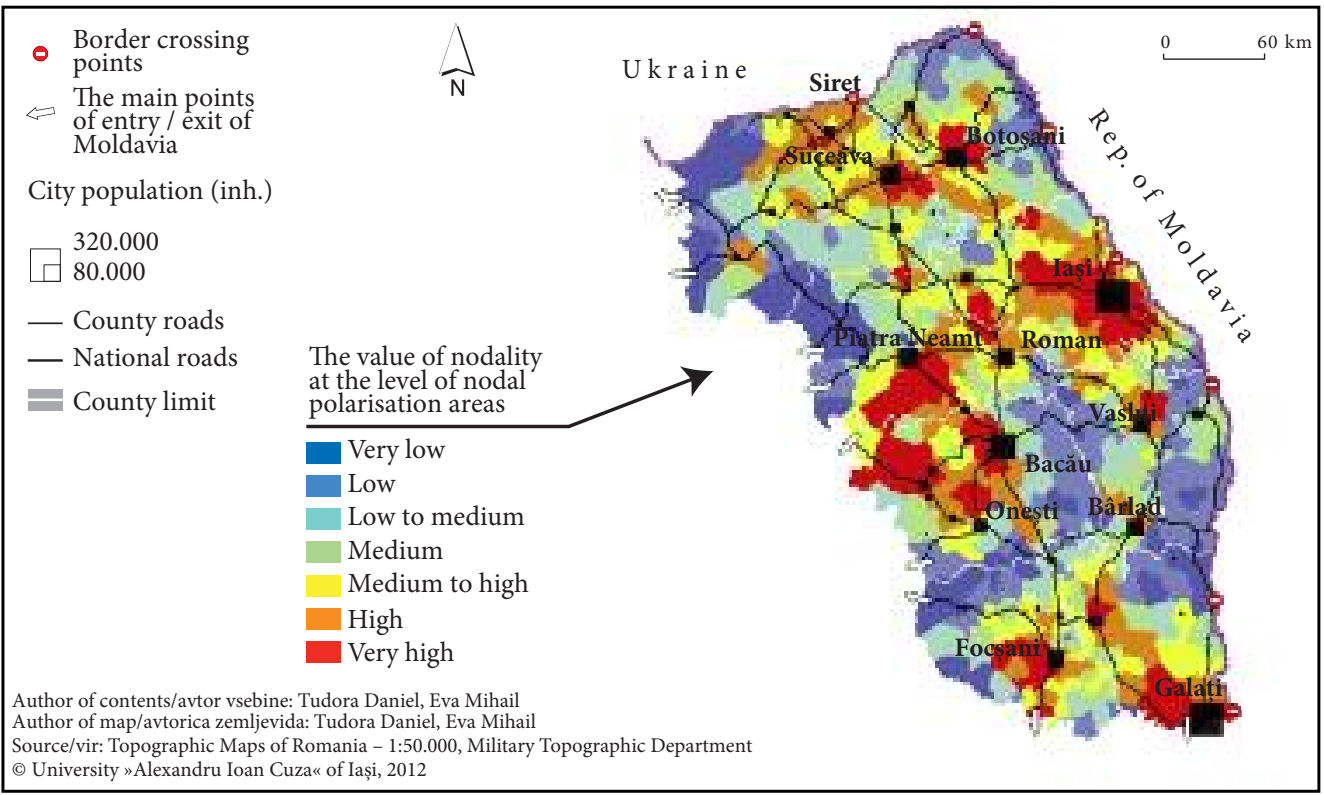

Figure 6: The value of nodality at the communal and nodal polarisation areas level.

- Consecutive coupling the county and national roads linking directly the cities of Botoşani and Iaşi may do the nodality transfer from the northern extremity of Moldavia to the main nodal point of the region, Iași, more easily. This sort of route would regard the balance created by the urban couple Suceava Botoșani, would shorten with approximately $50 \mathrm{~km}$ the distance between the border crossing point of Siret and Iași Cities, providing at the same time the revitalization of some peripheral rural areas like those situated in the northern part of the Iasi County.

Depending on the aims of each particular study, the insufficiencies generated by the analysis at the level of nodal spaces may be further corrected by replacing them with an administrative maillage, such as communal clippings.

\section{Conclusion}

The article proposes a glossary suitable for reticular environments. Its advantage comes from the finely epistemological delimitations between closely related terms such as gross nodality, adjusted nodality, total nodality, reticular capilarization and reticularity. The conceptual limits between different terms are being established from the perspective of the methodology applicable to each of them.

Furthermore, the methodology allows the conversion of concepts in quantitative benchmarks, subsequently benefiting from the advantage of being easily transposable into cartographic materials. Using them can be a starting point in territorial planning processes due to transversal dimension of indicators. For example, the values of total nodality provide information about the existence of nodal regions and their polarising centres, about discontinuities inserted between different homogenous structures or about the subjacent dimension of some territorial points that can constitute pivotal areas in shaping future policies aimed at strengthening territorial cohesion or competitiveness.

\section{Acknowledgements}

The research reported in this paper is funded by the Romanian National Council of Scientific Research in Higher Education (CNCSIS) as part of the research project IDEI 1987. We would also like to thank 
the Department of Geography of the University »Alexandru Ioan Cuza« of Iasi for the permanent support during the research project and the anonymous referees for their constructive comments and useful recommendations.

\section{References}

Banister, D. 2002: Transport planning. London.

Berdica, K. 2002: An introduction to road vulnerability: what has been done, is done and should be done. Transport policy 9-2. DOI: http://dx.doi.org/10.1016/S0967-070X(02)00011-2

Berke, E. M., Shi, X. 2009: Computing travel time when the exact address is unknown: a comparison of point and polygon ZIP code approximation methods. International Journal of Health Geographics 8-1. DOI: http://dx.doi.org/10.1186/1476-072X-8-23

Black, W. R. 2003: Transportation: a geographical analysis. New York.

Combes, P. P., Lafourcade, M. 2005: Transport costs: measures, determinants, and regional policy implications for France. Journal of economic geography 5-3. DOI: http://dx.doi.org/10.1093/jnlecg/lbh062

Curl, A., Nelson, J. D., Anable, J. 2011: Does accessibility planning address what matters? A review of current practice and practitioner perspectives. Research in transportation business \& management 2. DOI: http://dx.doi.org/10.1016/j.rtbm.2011.07.001

Debrie, J., Eliot, E., Soppe, M. 2005: Un modèle transcalaire des nodalités et polarités portuaires: exemple d'application au port de Hambourg. Mappemonde 79. Internet: http://mappemonde.mgm.fr/num7/ articles/art05304.html

Ducruet, C. 2008: Typologie mondiale des relations ville-port. CyberGeo. Article no. 417. http://dx.doi.org/ $10.4000 /$ cybergeo. 17332

Earth remote sensing data analysis centre. Internet: http://www.gdem.aster.ersdac.or.jp/search.jsp (15. 10.2011).

Fleming, D. K., Hayuth, Y. 1994: Spatial characteristics of transportation hubs: centrality and intermediacy. Journal of transport geography 2-1. DOI: http://dx.doi.org/ 10.1016/0966-6923(94)90030-2

Freeman, L. C. 1979: Centrality in social networks: Conceptual clarification. Social networks 1-3.

Gravelius, H. 1914: Flusskunde. Berlin.

INS 2002: Census of population and dwellings. National institute of statistics, Bucharest, Romania.

Knowles, R. D. 2006: Transport shaping space: the differential collapse of time/space. Journal of transport geography 14-6. DOI: http://dx.doi.org/10.1016/j.jtrangeo.2006.07.001

Knowles, R. D., Shaw, J., Docherty, I. 2008: Transport geographies: mobilities, flows and spaces. Malden.

Matthiessen, C. W., Schwarz, A. W., Find, S. 2002: The top-level global research system, 1997-1999: Centres, networks and nodality. An analysis based on bibliometric indicators. Urban studies 39, 5-6. DOI: http://dx.doi.org/0.1080/00420980220128372

Matthiessen, C. W., Schwarz, A. W., Find, S. 2006: World cities of knowledge: research strength, networks and nodality. Journal of knowledge management 10-5.

MTD 1992: Topographic maps of Romania, 1:50.000, Military topographic department, Ministry of national defense, Bucharest.

Mérenne, E. 1995: Géographie des transports. Paris.

Muntele, I., Groza, O., Țucănașu, G., Rusu, A., Tudora, D. 2010: Calitatea infrastructurii de transporturi ca premisă a diferențierii spațiilor rurale din Moldova. Iași.

Rathert, D. 2003: ArcScript Linear Proprieties. Internet: http://arcscripts.esri.com/details.asp?dbid=12789 (15.10.2011).

Rodrigue, J. P., Comtois, C., Slack, B. 2009: The geography of transport systems. New York.

Salonen, M., Toivonen, T., Cohalan, J. M., Coomes, O. T. 2011: Critical distances: comparing measures of spatial accessibility in the riverine landscapes of Peruvian Amazonia. Applied geography 32-2. DOI: http://dx.doi.org/10.1016/j.apgeog.2011.06.017

Sappington, J. M., Longshore, K. M., Thompson, D. B. 2007: Quantifying landscape ruggedness for animal habitat analysis: a case study using desert bighorn sheep in the Mojave Desert. Journal of wildlife management 71-5.

Shaw, S. L. 2006: What about time in transportation geography? Journal of transport geography 14. DOI: http://dx.doi.org/10.1016/j.jtrangeo.2006.02.009.

Taaffe, E. J., Gauthier, H. L., O'Kelly, M. E. 1996: Geography of transportation. New Jersey. 